\title{
Bilateral rupture of the Achilles tendon in patients on steroid therapy
}

\author{
JOHN F. HAINES \\ From the Orthopaedic Department, Park Hospital, Davyhulme
}

SUMMARY Three patients are presented who sustained bilateral rupture of the Achilles tendon while on systemic steroid therapy for chest disease; a fourth patient with polymyalgia rheumatica on steroids is also presented. This is further evidence that tendon rupture can be a direct complication of steroid treatment. The English-language literature on bilateral Achilles tendon rupture is reviewed.

Despite many papers discussing the treatment of Achilles tendon rupture few of them mention associated predisposing factors other than trauma or cases of bilateral rupture. ${ }^{1}$ Bilateral rupture of the Achilles tendon is an unusual occurrence, and 4 patients are presented here with this condition.

\section{Case reports}

\section{CASE 1}

An 86-year-old man was referred to the orthopaedic department on 10 April 1981 with bilateral heel pain. The left heel had suddenly become painful while walking 10 days earlier, and 5 days later the right heel did likewise. On examination he had a complete rupture of both Achilles tendons, with a tender palpable gap in both tendons $3 \mathrm{~cm}$ proximal to their insertions. Plantar flexion of the foot was absent on performing the calf compression test. ${ }^{2}$

He had a 4-year history of chronic obstructive airways disease such that in January 1981 he was started on systemic steroid therapy. For the 3 months prior to presentation he had taken between 10 and 15 mg prednisolone daily. He was on no other medication apart from occasional analgesia. There was no clinical, radiological, biochemical, or serological evidence of generalised arthropathy, gout, or other disease process.

In view of his age, poor chest condition, and delay in presentation it was decided to treat him by early mobilisation. He was given $\frac{3}{8}$ inch $(1 \mathrm{~cm})$ heel raises and attended the physiotherapy department for local treatments and mobilisation. His prednisolone dosage was reduced to $5 \mathrm{mg}$ daily over a period of one

Accepted for publication 6 September 1982.

Correspondence to Mr J. F. Haines, FRCS, Park Hospital, Moorside Road, Davyhulme, Manchester. month. During this time the pain settled and his mobility improved sufficiently to allow him to return home.

CASE 2

A 55-year-old man presented to the medical department with pain in both heels on 3 December 1979. Five days before this he had experienced pain in his left heel followed 3 days later by more severe pain. His right heel started to be painful at the same time.

He was initially thought to be suffering from a deep venous thrombosis, but further examination on the same day showed that he had a complete rupture of the left Achilles tendon. The right Achilles tendon was swollen and tender but without a palpable gap, and there was normal movement of the foot on compression of the calf. This was diagnosed as a partially ruptured Achilles tendon.

He had long-standing chronic obstructive airways disease and for 5 years since 1974 had been taking oral prednisolone varying in dose from 2 to $30 \mathrm{mg}$ daily. His other medication was salbutamol inhaler; beclomethasone inhaler; slow aminophylline; frusemide; and slow potassium tablets. There was no evidence of generalised arthropathy.

The left leg was treated in a short leg equinus plaster for 10 weeks. The right leg was treated by bed rest for 3 weeks until the tender swelling had settled. Full activity was delayed until the plaster was removed. He was then mobilised with $\frac{3}{8}$ inch $(1 \mathrm{~cm})$ heel raises. He has had no further problems with his Achilles tendons despite remaining on $15 \mathrm{mg}$ prednisolone daily.

CASE 3

A 57 year-old man presented to the orthopaedic outpatient department in May 1981 with a 3-week 
history of pain in both heels. The pain had come on suddenly when he got out of bed one morning and caused difficulty with walking. On examination both Achilles tendons were swollen and tender $2 \mathrm{~cm}$ above their insertion, with some associated bruising. Full ankle movements were present, but plantar flexion against resistance gave pain. There was normal movement of the feet on compression of the calf. This was diagnosed as partial rupture of both Achilles tendons.

He had been asthmatic for many years, taking prednisolone $10 \mathrm{mg}$ daily for 12 years since 1969 . He was on no other medication, and there was no evidence of generalised arthropathy.

He was treated by reduced activity and heel raises. Complete recovery followed over a period of 5 months.

\section{CASE 4}

A 79-year-old man was first seen in the orthopaedic outpatient department on 30 April 1982 with a 6-week history of pain behind both heels which had started spontaneously. On examination he had a complete rupture of the left Achilles tendon and a partial rupture of the right-thickened and tender but intact without a gap.

In 1980 he had an adenocarcinoma of the large bowel treated by partial colectomy. There was no evidence of recurrence. In 1981 he developed polymyalgia rheumatica, which was treated with prednisolone. At the time of presentation he had been on a maintenance dose of $5 \mathrm{mg}$ prednisolone daily for one year. He was also taking intermittent indomethacin. There was no evidence of generalised arthropathy.

He was treated with bilateral heel raises, but 3 weeks later examination showed complete rupture of both Achilles tendons. He was, however, able to remain with an acceptable degree of mobility, and no further treatment was needed.

\section{Discussion}

Tendon ruptures at various sites have been reported in association with many factors such as rheumatoid arthritis, ${ }^{3}$ systemic lupus erythematosus, ${ }^{4}$ gout, ${ }^{5}$ primary and secondary hyperparathyroidism, ${ }^{67}$ chronic renal failure on dialysis, ${ }^{8}$ hyperlipoproteinaemia type II $^{9}$ and local steroid injections. ${ }^{10}$ The part played by systemic steroid therapy is disputed.

A recent paper by Cooney et al. ${ }^{11}$ suggested that the most important aetiological factor in bilateral patellar tendon rupture was the basic disease process rather than coincident systemic steroid treatment. This was based on the fact that no cases of bilateral patellar tendon rupture have been reported in which the patient was taking steroids for a nonrheumatic disease such as asthma.

With the 4 cases reported here the Englishlanguage literature contains 10 examples of bilateral Achilles tendon rupture with sufficient documentation to allow comment. ${ }^{12-17}$ More are mentioned in series of traumatic ruptures but without any clinical details. $^{18} 18$

Table 1 presents the relevant details of the 10 cases. Five were associated with chest disease and systemic steroid therapy. Only 3 were associated with a rheumatic disease and steroid therapy, and 2 were healthy individuals. This is different from the situation at the knee, ${ }^{11}$ mentioned earlier, and indicates that steroid therapy alone can play a major role in causing bilateral Achilles tendon rupture.

The mechanism of action is uncertain. Several workers have shown that Achilles tendon rupture

Table 1 Clinical details of patients with bilateral Achilles tendon rupture

\begin{tabular}{|c|c|c|c|c|c|c|c|}
\hline Author & Reference & Age & Sex & Diagnosis & Oral steroids & Previous pain & Trauma \\
\hline Cowan & 13 & 52 & $\mathbf{M}$ & Chronicdiscoid LE & $\begin{array}{l}\text { Triamcinolone } 8-16 \mathrm{mg} \text { for } 5 \\
\text { months }\end{array}$ & + & No \\
\hline Lee & 14 & 61 & $\mathbf{M}$ & SLE + polyarthritis & $\begin{array}{l}\text { Prednisolone } 10-20 \mathrm{mg} \text { for } 3 \\
\text { years }\end{array}$ & + & No \\
\hline Smaill & 12 & 68 & $\mathbf{M}$ & Chronic bronchitis & $\begin{array}{l}\text { Prednisolone } 7 \cdot 5-30 \mathrm{mg} \text { for } 16 \\
\text { months }\end{array}$ & + & No \\
\hline Melmed & 16 & 68 & $\mathbf{M}$ & Shortness of breath & Betamethasone $3 \mathrm{mg}$ for 2 years & - & No \\
\hline Lindenmaier & 17 & 28 & $\mathbf{F}$ & Healthy & Nil & - & Yes \\
\hline $\begin{array}{l}\text { Mayer } \\
\text { Case } 1 \text { here }\end{array}$ & 15 & $\begin{array}{l}46 \\
86\end{array}$ & $\begin{array}{l}\mathbf{F} \\
\mathbf{M}\end{array}$ & $\begin{array}{l}\text { Healthy } \\
\text { Chronic bronchitis }\end{array}$ & $\begin{array}{l}\text { Nil } \\
\text { Prednisolone } 10-15 \mathrm{mg} \text { for } 3\end{array}$ & - & Yes \\
\hline & & & & Chronic bronchitis & $\begin{array}{l}\text { Prednisolone } 10-15 \mathrm{mg} \text { for } 3 \\
\text { months }\end{array}$ & - & No \\
\hline Case 2 here & & 35 & $\mathbf{M}$ & Chronic bronchitis & $\begin{array}{l}\text { Prednisolone } 2-30 \mathrm{mg} \text { for } 5 \\
\text { years }\end{array}$ & + & No \\
\hline Case 3 here & & 57 & $\mathbf{M}$ & Chronic bronchitis & $\begin{array}{l}\text { Prednisolone } 10 \mathrm{mg} \text { for } 12 \\
\text { years }\end{array}$ & & No \\
\hline Case 4 here & & 79 & $\mathbf{M}$ & Polymyalgia rheumatica & Prednisolone $5 \mathrm{mg}$ for 1 year & + & No \\
\hline
\end{tabular}


often occurs at sites of local degeneration, as shown in biopsy specimens. ${ }^{16} 1720$ Clinically such patients have pain in the Achilles tendon prior to rupture. Of the 10 cases of bilateral Achilles tendon rupture 5 had significant pain prior to rupture, and case 3 presented here was at the stage of painful partial rupture.

Steroids probably act by suppressing the repair of degenerated or partially ruptured tendons to such an extent that complete rupture can occur after a minor incident. It does not appear to be related to dose of steroid or length of treatment.

Although Achilles tendon function is not essential for the upright posture or walking, it is still important to appreciate that tendon rupture is a complication of steroid therapy. Thus, as in cases 2 and 3 presented here, measures can be taken to prevent degeneration or partial rupture progressing to complete rupture. Such measures would include stopping steroid therapy if possible, raised heels, or rest in plaster-ofParis as indicated. Case 4 indicates that heel raises are not a particularly effective protection, but they are a reasonable compromise in the elderly patient who would be rendered immobile by a plaster.

I thank Mr E. J. Hargadon and Dr D. Bainbridge for permission to present their patients.

\section{References}

1 Barfred T. Achilles tendon rupture. Acta Orthop Scand (Suppl) 1973; 152: 3-126.

2 Thompson T C. A test for rupture of the tendo Achillis. Acta Orthop Scand 1962; 32: 461.

3 Rask M A. Achilles tendon rupture owing to rheumatoid disease. JAMA 1978; 239: 435-6.
4 Rascher J J, Marcolin L, James P. Bilateral sequential rupture of the patellar tendon in systemic lupus erythematosus. J Bone Joint Surg 1974; 56A: 821-2.

5 Mahoney P G, James P D, Howell C J, Swannell A J. Spontaneous rupture of the Achilles tendon in a patient with gout. Ann Rheum Dis 1981; 40: 416-8.

6 Preston E T. Avulsion of both quadriceps tendons in hyperparathyroidism. JAMA 1972; 221: 406.

7 Cirincione R J, Baker B E. Tendon ruptures with secondary hyperparathyroidism. A case report. J Bone Joint Surg 1975; 57A: 852.

8 Morein G, Goldschmidt Z, Pauker M, Seelenfreund M, Rosenfield J B, Fried A. Spontaneous tendon ruptures in patients treated by chronic haemodialysis. Clin Orthop 1977; 124: 209-13.

9 Haacke H, Parwaresch M R. Spontaneous rupture of the Achilles tendon-a sign of hyperlipoproteinaemia (HLP) type II. Klin Wochenschr 1979; 57: 397-400.

10 Unverforth L J, Olix M L. The effect of local steroid injections on tendons. J Bone Joint Surg 1973; 55A: 1315.

11 Cooney L M, Aversa J M, Neuman J H. Insidious bilateral infrapatellar tendon rupture in a patient with systemic lupus erythematosus. Ann Rheum Dis 1980; 39: 592-5.

12 Smaill G B. Bilateral rupture of Achilles tendon. Br Med J 1961; i: $1657-8$.

13 Cowan M A, Alexander S. Simultaneous bilateral rupture of Achilles tendon due to triamcinolone. Br Med J 1961; i: 1658.

14 Lee M L H. Bilateral rupture of Achilles tendon. BrMed J 1961; i: 1829.

15 Mayer J H. Bilateral rupture of Achilles tendon. Br Med J 1961; i: 1830.

16 Melmed E P. Spontaneous bilateral rupture of the calcaneal tendon during steroid therapy. J Bone Joint Surg 1965; 47B: $104-5$.

17 Lindenmaier H L, Koch H K. The bilateral subcutaneous rupture of the Achilles tendon-a rare injury. Unfallchirurgie 1980; 6: 256-60.

18 Nistor L. Surgical and non-surgical treatment of Achilles tendon rupture. J Bone Joint Surg 1981; 63A: 394-9.

19 Inglis A E, Sculpo T P. Surgical repair of ruptures of the tendo Achillis. Clin Orthop 1981; 156: 160-9.

20 Fox JM, Blazina M E, Jobe F W, et al. Degeneration and rupture of Achilles tendon. Clin Orthop 1975; 107: 221-4. 